\title{
Experimental and Numerical Studies of Magnetorheological (MR) Damper
}

\author{
S. K. Mangal and Ashwani Kumar \\ Mechanical Engineering Department, PEC University of Technology, Chandigarh 160012, India \\ Correspondence should be addressed to S. K. Mangal; skmangal_pec@rediffmail.com
}

Received 8 December 2013; Accepted 15 January 2014; Published 25 February 2014

Academic Editors: R. Hong and G. Xie

Copyright ( 2014 S. K. Mangal and A. Kumar. This is an open access article distributed under the Creative Commons Attribution License, which permits unrestricted use, distribution, and reproduction in any medium, provided the original work is properly cited.

\begin{abstract}
The design of a MR damper, consisting of piston and cylinder arrangement, is presented in this paper. In this paper, a $2 \mathrm{D}$ axisymmetric model based on finite element method (FEM) concept has been developed on the ANSYS platform to analyze and examine the MR damper characteristics. Based on the FEM model, a prototype of the MR damper is fabricated and tested experimentally in the semi active vibration laboratory of the department. The comparison of both these model analyses indicates that the FEM based model is effectively portraying the experimental behavior of the MR damper in terms of its damping force. The results obtained in this paper will be helpful for the designers to create more efficient and reliable MR dampers and also to predict its damping force characteristics.
\end{abstract}

\section{Introduction}

Nowadays, handling stability and ride comfort are considered very important features of an automotive driving. Semiactive vibration control systems in automobile suspension had received a great attention among the researchers community as the smart materials are being used in these devices. Further, these smart materials have the characteristics of rapid reversible response phenomenon at low power consumption. The smart materials have multiple properties (electrical, magnetic, mechanical, and thermal) and can also transform energy. These properties can be altered very easily using some external fields, for example, magnetic or electric, and so forth. Magnetorheological (MR) fluids are one of such smart material that exhibits drastic and reversible change in its rheological properties, for example, elasticity, plasticity, viscosity, and so forth, which mainly depend upon the intensity of the magnetic field [1] being applied on it. The discovery of the MR fluids is credited to Jacob Rabinow at the US National Bureau of Standard in 1948 [2]. The MR fluids are the most commonly used fluids in the dampers to achieve variable damping coefficient of it. It, thus, makes the vibration control more effective in wide spectrum of frequencies which is more suitable for the automotive applications. A typical magnetorheological damper consists of cylinder, piston, electromagnetic coil, and the MR fluid which is enveloped in a cylinder. This arrangement is shown in Figure 1. In this paper, a $2 \mathrm{D}$ axisymmetric model based on finite element method (FEM) concept is built on the ANSYS platform. Based on it, a prototype of the MR damper is fabricated and tested in the laboratory. Based on these model analyses, it can be stated that the FEM based model is effectively portraying the experimental behavior of a MR damper in terms of its damping force.

\section{FEM Modeling of MR Damper}

Finite element method (FEM) simulates a physical system or assembly's behavior by dividing the geometry of the system into a large number of small elements of standard shapes, formulates system equations, applies boundary conditions in terms of loads and constraints, and then solves the modified system equations for the unknown field variables of the interest, for example, displacement, strain, stresses, temperature, magnetic flux density, and so forth. The ANSYS [3] is used in this work as it is universally accepted FEM software. 


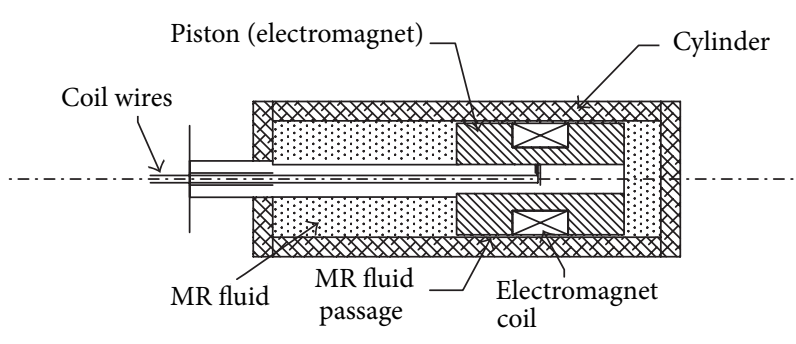

FIGURE 1: Schematic representation of MR damper.

TABLE 1: Dimensions of prototype MR damper.

\begin{tabular}{llc}
\hline Sr. no. & Parameter & Dimensions $(\mathrm{mm})$ \\
\hline 1 & Pole length $(L)$ & 23 \\
2 & Distance between the poles $(\ell)$ & 22 \\
3 & Radius of the piston $(R)$ & 23 \\
4 & Piston rod radius $(r)$ & 06 \\
5 & Radial distance from piston rod & 07 \\
& to coil width $(H)$ & 01 \\
6 & Clearance between piston and & 08 \\
7 & cylinder $(h)$ & \\
\hline
\end{tabular}

2.1. ANSYS Modeling of MR Damper. Study of the MR damper is a promising topic as it provides a controllable damping force just by varying the current in its electromagnetic coil. The current can be supplied by the battery of an automotive vehicle. A number of researchers have begun modeling and designing of these MR dampers from different aspects of design with the help of finite element method (FEM). This has resulted in different designs of MR dampers having different geometry, effective range, and working principles [4]. The damping force being produced by a MR damper depends mainly on the magnetic field induced in the working fluid clearance between piston and cylinder [5]. Based on the extensive literature survey, the magnetic circuit of the MR damper is shown in Figure 2. The MR damper having dimensions/parameters as listed in Table 1 is then fabricated. The following steps are used in a static magnetic analysis of the MR damper in ANSYS platform.

(i) Create the physics environment.

(ii) Build and mesh the model and assign physics attributes to each region within the model.

(iii) Apply boundary conditions and loads, that is, excitation.

(iv) Obtain the nodal solution.

(v) Review and post processing of the results.

The MR damper is an axisymmetric solid subjected to axisymmetric loading and thus a $2 \mathrm{D}$ FEM modeling is sufficient for this prototype (Figure 3 ) analysis. The piston, MR fluid gap, and the cylinder are assumed to be stationary components that complete the magnetic circuit around the

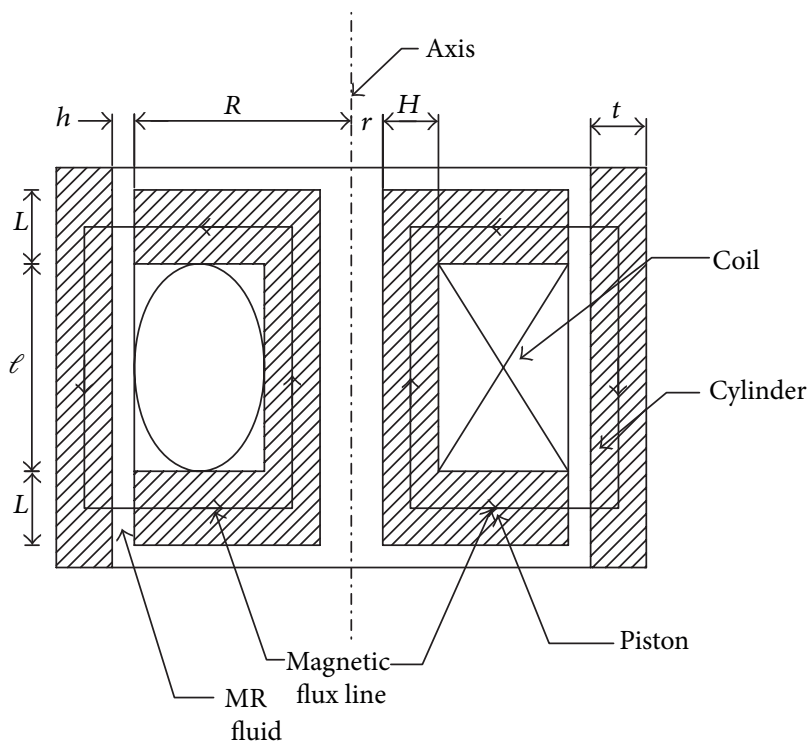

Figure 2: Magnetic circuit of MR damper.

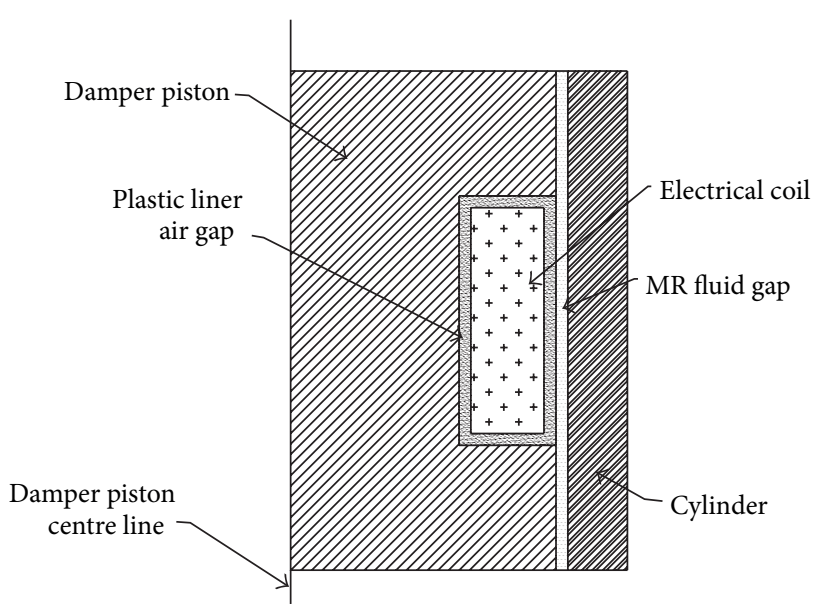

Figure 3: 2D axisymmetric model of MR damper in the ANSYS.

electromagnetic coil. In the ANSYS modeling, 350 turns (Figure 4) for the electromagnetic coil are used to determine the magnetic flux density. The electrical current is varied in the coil to get the varied magnetic flux density. In the modeling, the piston and cylinder material is taken as steel having relative permeability of 2000 . The relative permeability of coil is taken as 1 while the relative permeability of the MR fluid is taken as 6 . The magnetic permeability of the free space is taken as $\left(\mu_{o}\right) 4 \pi \times 10^{-7} \mathrm{H} / \mathrm{m}[6]$.

2.1.1. Element Description. The ANSYS software includes a variety of elements in its library and one can choose any one of these element to model the electromagnetic phenomena of the MR damper. From literature survey, it is decided to use PLANE13 element which is a 2D quadrilateral coupled-fieldsolid element containing four nodes. The PLANE13 element has 2D magnetic, thermal, electrical, and piezoelectric field capability with limited coupling between the fields. The 


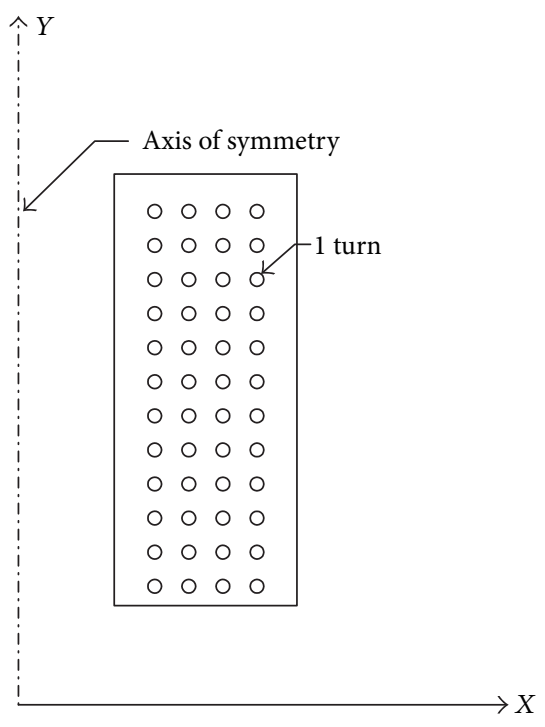

FIGURE 4: Electrical coil cross-section.

element also has nonlinear magnetic capability for modeling of the $B-H$ curves.

2.1.2. Input Data. The element input data includes coordinates of the four nodes and magnetic and electrical properties of each element. The metric units are used and are specified through the EMUNIT command. The EMUNIT also determines the value of $\mu_{0}$ (free-space permeability) which is given as $4 \pi \times 10^{-7} \mathrm{H} / \mathrm{m}$. In addition to the $\mu_{0}$, the relative permeability for each material is also specified through the $\mu_{x}$. Current density is another input data for the software which is to be applied to the coil area.

2.1.3. Output Data. The output solution of the software, which is associated with an element, will be in the following form:

(i) nodal degrees of freedom included in the overall nodal solution,

(ii) additional element output, for example, electromagnetic components.

The element output directions are parallel to the element coordinate system. In the ANSYS software, one defines the magnetic flux density as $B_{x}$ and $B_{y}$ along the $x$ - and $y$-axes, respectively. The term $B_{\text {SUM }}$ is giving the vector sum of these $B s$ and is determined as

$$
B_{\mathrm{SUM}}=\sqrt{B_{X}^{2}+B_{Y}^{2}}
$$

2.1.4. Element Solution. Figure 5 shows $2 \mathrm{D}$ flux lines obtained in the ANSYS modeling of the MR damper around the electromagnetic coil. Figure 6(a) shows the axisymmetric $2 \mathrm{D}$ elemental solution in the form of the magnetic induction distribution while Figure 6(b) shows the spatial view of the same analysis. The flux density as vectors around

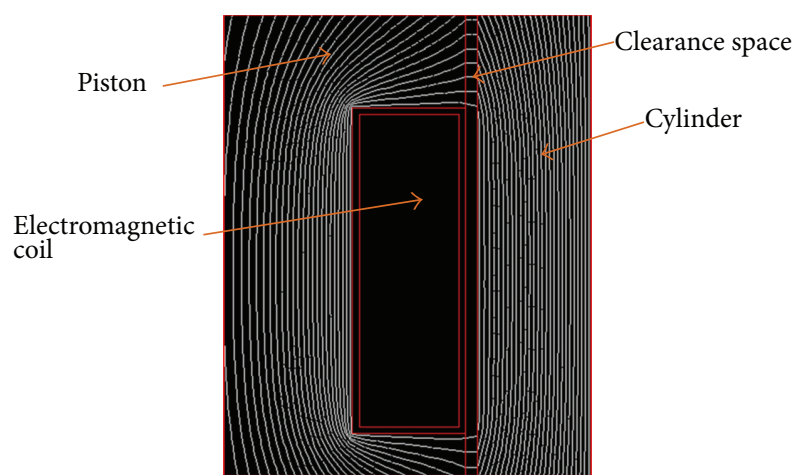

Figure 5: 2D flux lines around the electromagnetic coil.

TABLE 2: Magnetic flux density obtained from FEM model.

\begin{tabular}{lc}
\hline Current $(\mathrm{A})$ & Magnetic flux density (Tesla) \\
\hline 0.1 & 0.053 \\
0.2 & 0.106 \\
0.3 & 0.158 \\
0.4 & 0.211 \\
0.5 & 0.264 \\
0.6 & 0.317 \\
0.7 & 0.370 \\
\hline
\end{tabular}

the electromagnetic coil of the MR damper is shown in Figure 7.

The ANSYS model provides the nodal solution at the clearance space of the MR damper due to its magnetic induction. In this analysis, current is varied from 0 to $0.7 \mathrm{~A}$ in a step of $0.1 \mathrm{~A}$. The respective ANSYS result shows that magnetic flux density increases with the increase in the current applied to the MR damper. This phenomenon is shown quantitatively in Table 2 and qualitatively in Figure 8.

\section{Calculation of the Damping Force}

The damping force of the MR damper is calculated for the FEM model using the magnetic flux densities generated by the ANSYS. For this purpose, the relationship is developed between the shear stress $\left(\tau_{y}\right)$ and the magnetic flux density (B) for Lord MRF-122EG [7] using the graphical data given by the Lord Corp., Inc., USA. The resulting equation is shown in (2). The shear stress value, thus, obtained at various levels of magnetic flux density is subsequently substituted in (3) to get the damping force

$$
\begin{aligned}
\tau_{y}=( & \left.6.9 \times 10^{2}\right)+\left(4 \times 10^{4}\right) B-\left(1 \times 10^{5}\right) B^{2} \\
+ & \left(9.1 \times 10^{4}\right) \times B^{3} .
\end{aligned}
$$




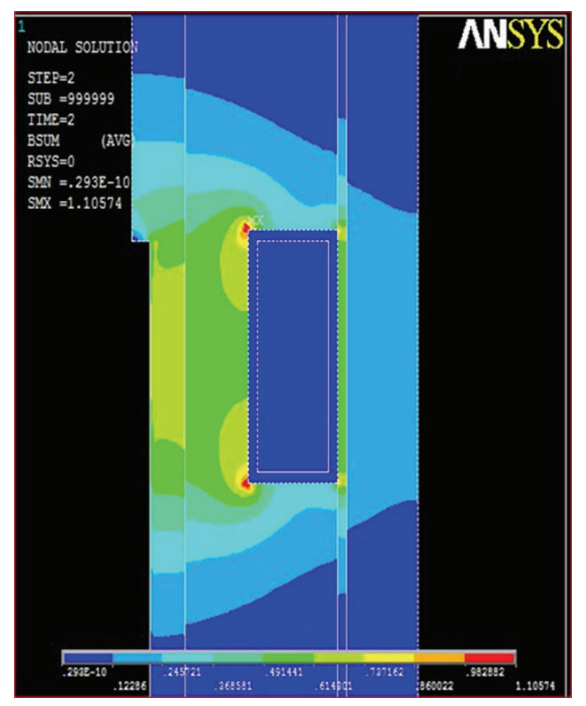

(a)

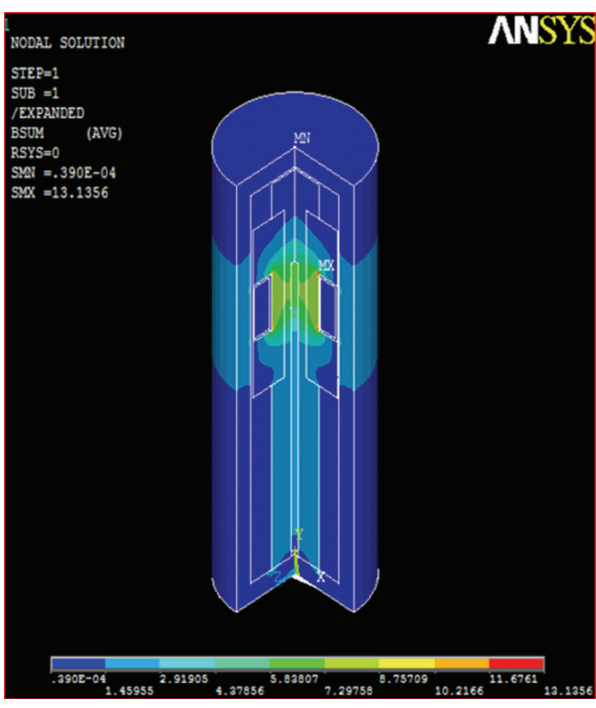

(b)

FIGURE 6: Elemental solution of the magnetic induction distribution: (a) 2D solution and (b) a spatial view.

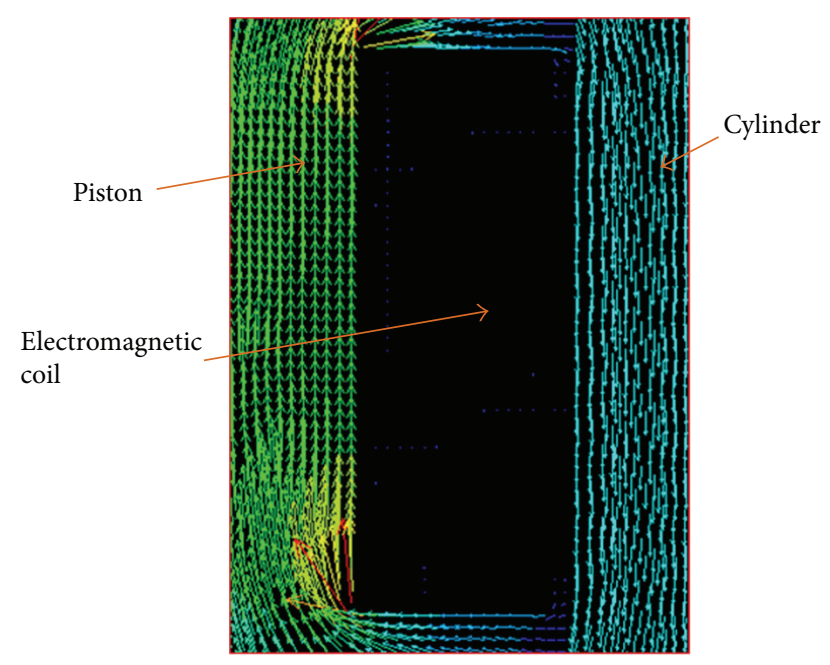

FIGURE 7: Flux density shown around electromagnetic coil as vectors.

According to the Bingham plastic model [8-10] of plates, the damping force $F_{D}$ is divided into an induced yield stress, $F_{t}$, and viscous components, $F_{\eta}$. This is given as

$$
\begin{aligned}
F_{D}=F_{\tau}+F_{\eta}= & \left(2.07+\frac{12 Q \eta}{12 Q \eta+0.4 w h^{2} \tau_{y}}\right) \frac{\tau_{y} L A_{p}}{h} \operatorname{sgn}(v) \\
& +\left(1+\frac{w h v}{2 Q}\right) \frac{12 \eta Q L_{t} A_{p}}{w h^{3}},
\end{aligned}
$$

where

$$
\begin{gathered}
Q=A_{p} \times v, \\
A_{p}=\frac{\pi}{4}\left(D^{2}-d_{o}^{2}\right),
\end{gathered}
$$

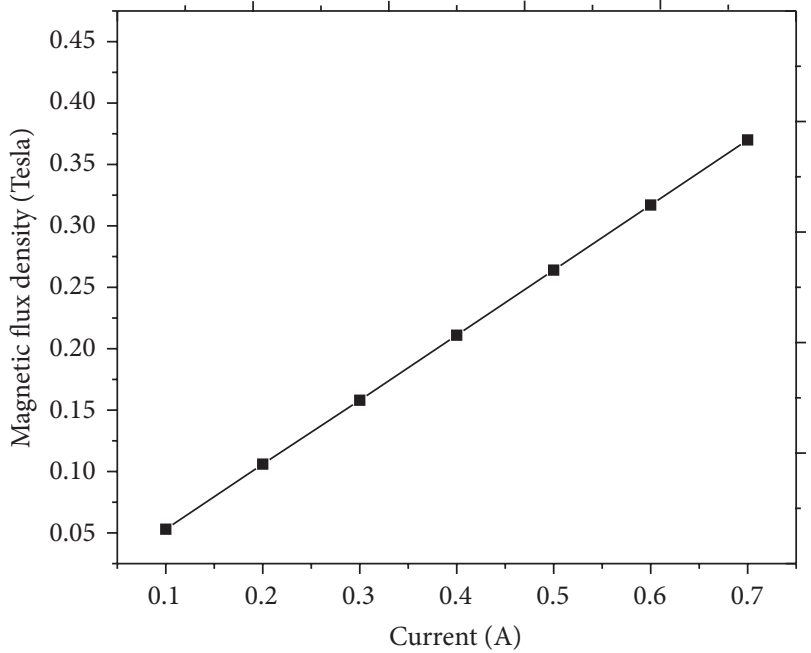

FIGURE 8: Magnetic flux density versus current (ANSYS model).

where $Q$ is the volumetric flow rate of the MR fluid, $A_{p}$ is the effective cross-sectional area of piston, $D$ is the diameter of the piston, $d_{o}$ is the diameter of the piston $\operatorname{rod}, v$ is the piston velocity, $\tau_{y}$ is the yield shear strength of the MR fluid, $\eta$ is the off-state (no magnetic field) viscosity of the MR fluid, $L$ is the effective axial pole length, $h$ is the gap between piston and cylinder, $L_{t}$ is the total axial pole length, $w$ is the mean circumference of the damper's annular flow path, and $\operatorname{sgn}(v)$ is used to consider the reciprocating motion of the piston.

The researchers $[11,12]$ have stated that one needs to include the effect of frictional forces $\left(F_{f}\right)$ of the system. As the friction exists in the contact surfaces of the movable and immovable parts of the MR damper, it cannot be ignored in 


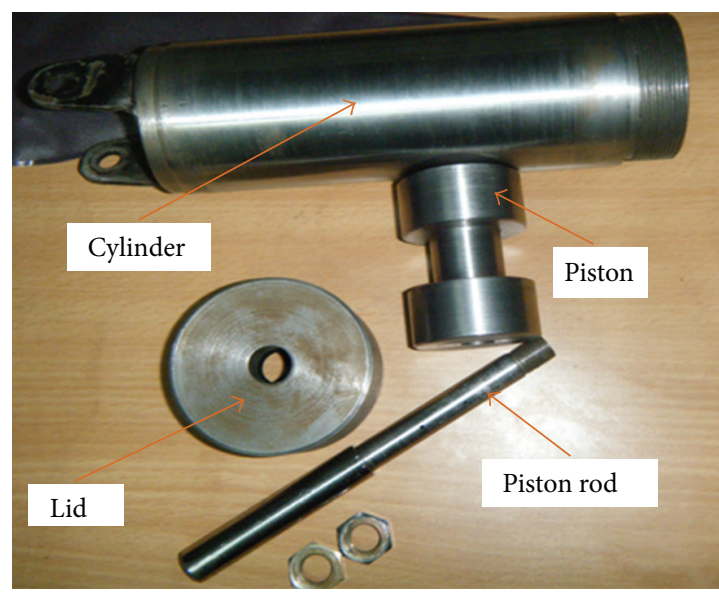

(a)

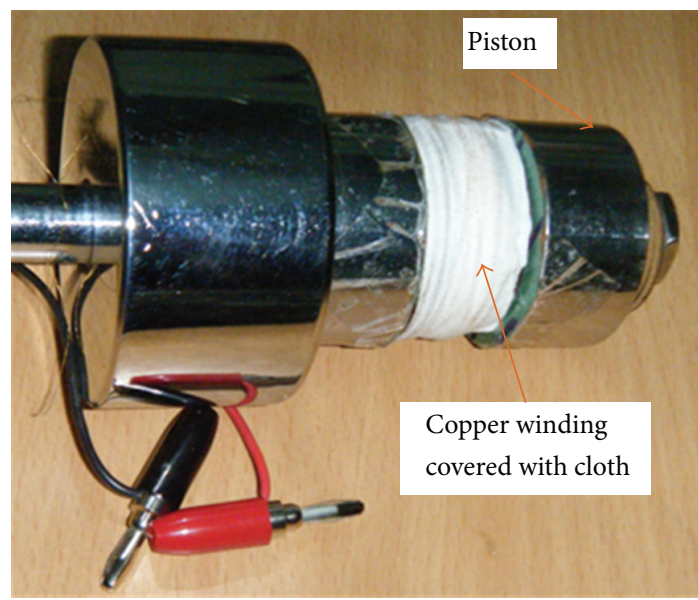

(c)

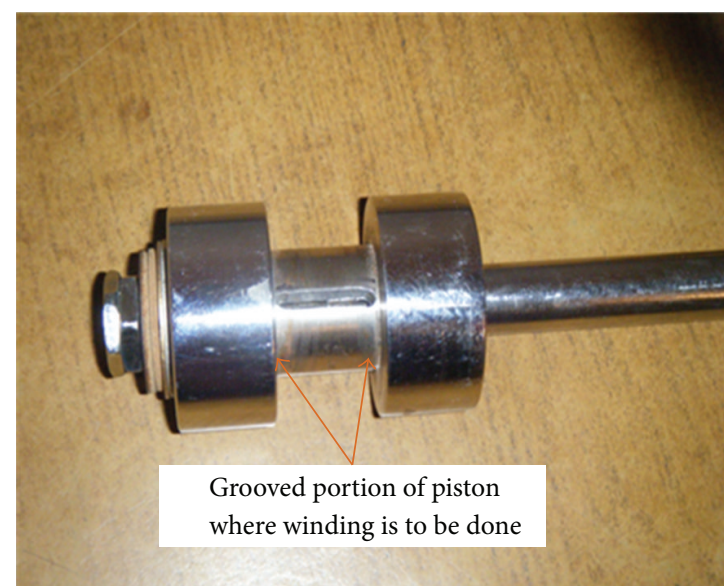

(b)

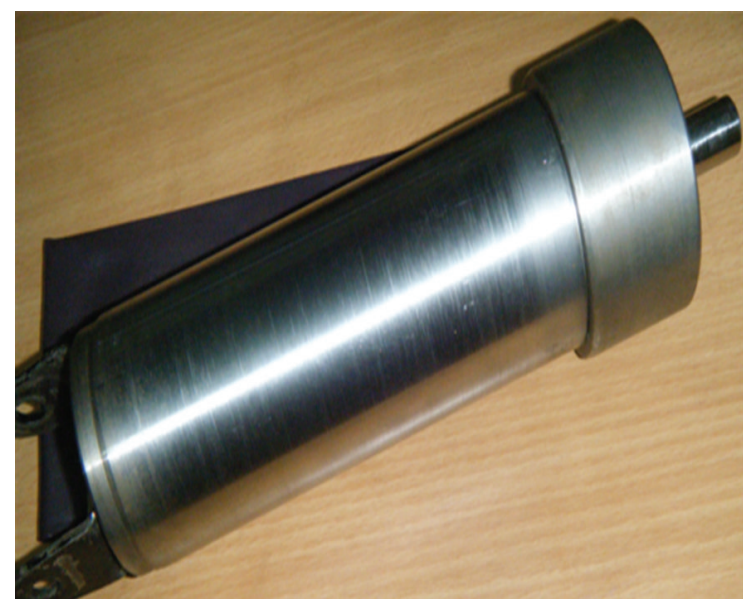

(d)

FIGURE 9: (a) Components of the prototype MR damper, (b) assembly of piston and piston rod, (c) assembled piston and its rod with copper winding covered with cloth, and (d) assembly of MR damper.

the analysis. Thus, the total damping force $\left(F_{\mathrm{TD}}\right)$ is the sum of $F_{t}, F_{\eta}$, and $F_{f}$ and is given as

$$
F_{\mathrm{TD}}=F_{\tau}+F_{\eta}+F_{f},
$$

where $F_{t}$ is the force component due to induced yield stress, $F_{\eta}$ is the viscous force component, and $F_{f}$ is the frictional force component. The total damping force is then calculated for the FEM model. The result of the total damping force is listed in Table 3.

\section{Experimental Study of MR Damper Force}

Based on the dimensions as selected in Table 1 and the FEM modeling, a prototype magnetorheological damperis fabricated. The various parts of the prototype MR damper and its complete assembly are shown in Figure 9. In the damper, MR fluid flows from an upper chamber to lower chamber and vice versa through the clearance space existing between the piston and cylinder. The prototype magnetorheological damper is tested for its performance by using MR fluid (LORD-MRF-122EG) in the semiactive vibration control
TABLE 3: Damping force at various current levels for FEM model and experimental damping force.

\begin{tabular}{lcc}
\hline Current (A) & $\begin{array}{c}\text { Damping force- } \\
\text { FEM model (N) }\end{array}$ & $\begin{array}{c}\text { Damping force- } \\
\text { experimental (N) }\end{array}$ \\
\hline 0.10 & 206.38 & 224.40 \\
0.20 & 303.20 & 327.66 \\
0.30 & 371.95 & 394.36 \\
0.40 & 418.33 & 436.77 \\
0.50 & 448.02 & 463.14 \\
0.60 & 466.67 & 481.73 \\
0.70 & 480.06 & 504.65 \\
\hline
\end{tabular}

laboratory. The setup of the laboratory is shown in Figure 10 where the damper is also shown mounted on the mechanical loading frame for its experimental performance analysis. The schematic diagram of the experimental set is shown in Figure 11.

The laboratory consists of an electrodynamic vibration (EDV) shaker having a rated sine force of $2000 \mathrm{~N}$ with 


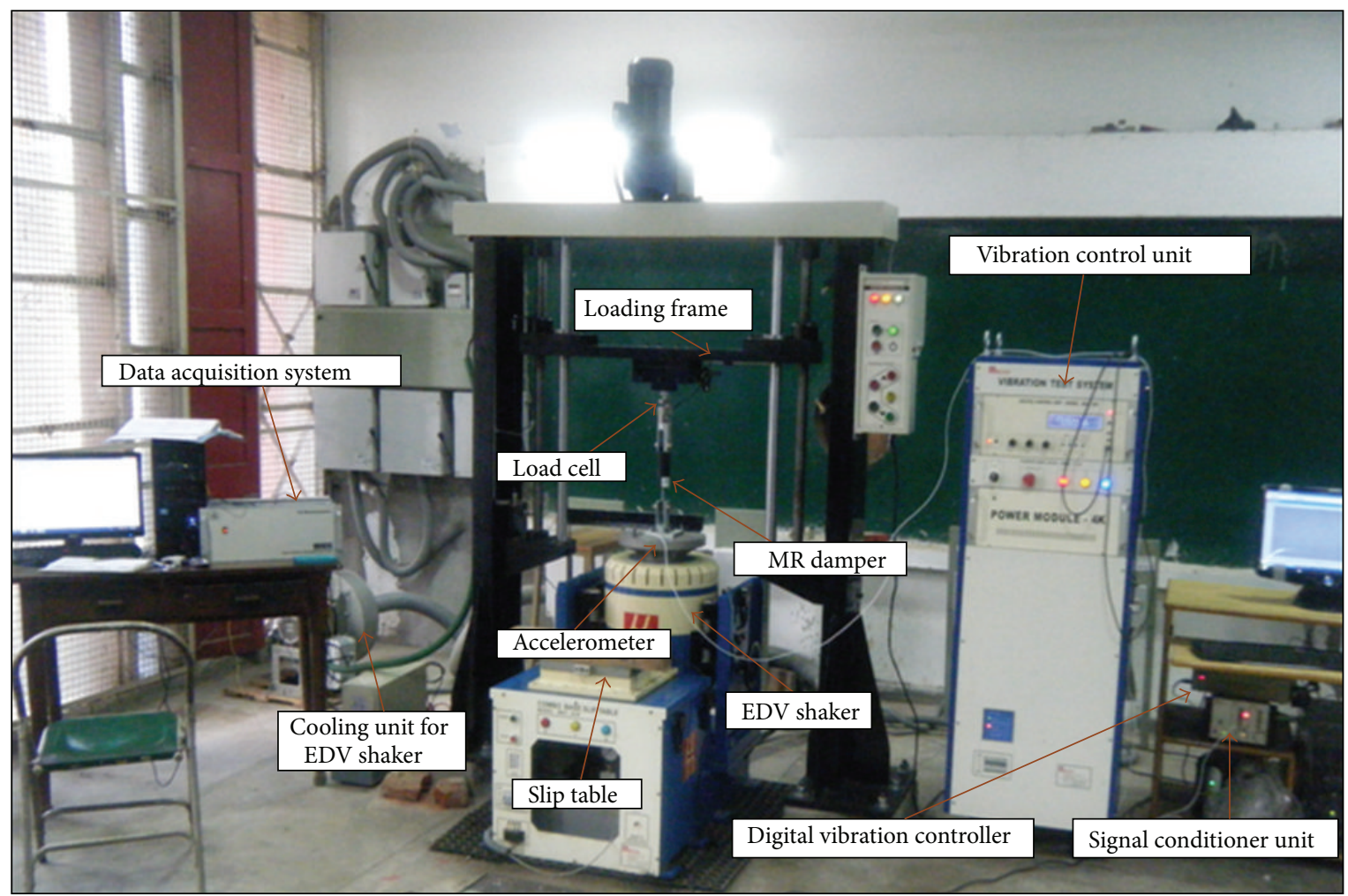

FIGURE 10: Experimental setup for the testing of MR damper (mounted).

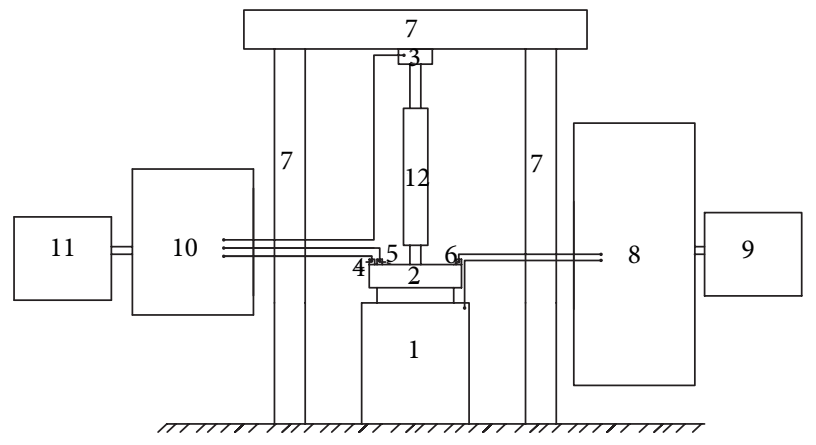

(1) EDV shaker

(7) Mechanical loading frame

(2) EDV shaker table

(8) Vibration test system

(3) Load cell

(9) Computer for vibration test system

(4) Accelerometer-I

(10) Data acquisition system (DAS)

(5) Displacement sensor

(6) Accelerometer-II

(11) Computer for DAS

(12) Prototype MR damper

Figure 11: The schematic diagram of the experimental setup.

a frequency range of 1 to $3500 \mathrm{~Hz}$. The rated peak to peak amplitude of the EDV shaker is $20 \mathrm{~mm}$. The amplitude of the vibration is set at a desired value by varying the gain of the vibration test system. The EDV shaker can be operated manually or by PC based control mode.
The shaker can also be used either for horizontal or vertical vibrational analysis. The shaker is controlled by PC based digital vibration controller cum analyzer having built-in signal conditioner unit. The shaker setup has a compatible PC based data acquisition and instrumentation system which gives the data in the form of force, velocity, displacement, and acceleration in real time manner. The system also includes a mechanical loading frame on which the damper is mounted vertically. The initial position of the piston in the cylinder of the MR damper is controlled either manually or by PC based control system. The piston is positioned near the bottom end of the cylinder of the MR damper during its experimental performance analysis. The test is performed for number of cycles at a fixed frequency of $1 \mathrm{~Hz}$ having the same gain which is set by vibration test system. The test is repeated under the same condition but at different current values supplied to the electromagnetic coil of the MR damper. The current is monitored and supplied through wonder box kit supplied by LORD Corp., Inc., USA [7]. The current is varied from $0.1 \mathrm{~A}$ to $0.7 \mathrm{~A}$ in a step of $0.1 \mathrm{~A}$. The experimental damping force experienced by the piston rod is sensed by a load cell which is fixed at the top of the MR damper while the displacement is recorded through a displacement sensor. The experimental damping force, thus, obtained is tabulated in Table 3 for different current setting. This damping force is compared with the FEM modeling results. These are compared qualitatively in Figure 12. The results of both models are giving nearly the same value of the total damping force over a wide range of input currents. 


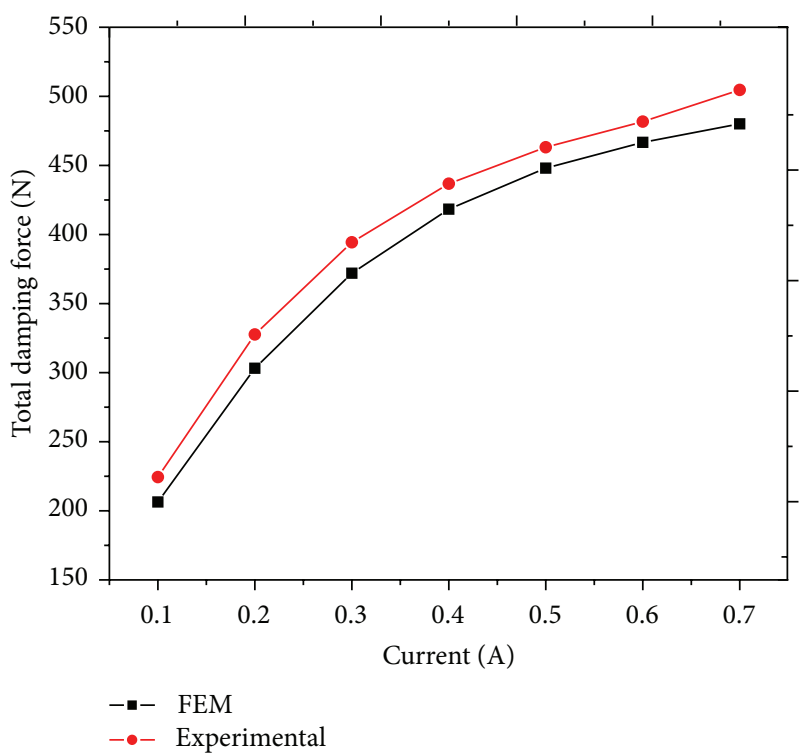

FIGURE 12: Comparison of damping force of the both models.

\section{Conclusion}

The MR fluids are the most commonly used fluids in MR dampers to achieve variable damping coefficient. In this paper, FEM modeling has been carried out on ANSYS platform for the fabricated MR damper. The total damping force has been determined using the magnetic flux density values obtained from the ANSYS analysis. Then, experimental damping force is obtained by performing the tests on the prototype MR damper in the laboratory at different input current. On comparison of these two modeling results, it is observed that the total damping forces of both models are giving nearly the same values over a wide range of input currents. It is observed from the various graphical results that the total maximum damping force experienced by the damper is around $500 \mathrm{~N}$ which occurs at $0.7 \mathrm{~A}$. It is concluded from this work that the FEM model effectively portrays the experimental behavior of a MR damper. The analysis adopted in this paper is adequate enough for the control and design of a MR damper. The results obtained in this paper will help the designers to create more efficient and reliable MR dampers and also to predict the damping force within the permissible error of engineering analysis.

\section{Nomenclature}

$A_{p}:$ Effective cross-sectional area of piston

$B: \quad$ Magnetic flux density

$D$ : Diameter of the piston

$F_{D}$ : Damping force

$F_{f}$ : Friction force component

$F_{\eta}$ : Viscous force components

$F_{\tau}: \quad$ Induced yield stress

$F_{\mathrm{TD}}$ : Total damping force

$H$ : Radial distance from piston rod to coil width
I: Current

L: Pole length

Q: Volumetric flow rate

$R$ : Radius of the piston

$d_{o}$ : Diameter of the piston rod

$h$ : Clearance between piston and cylinder

$\ell$ : Distance between the poles

$r$ : Piston rod radius

$t$ : Thickness of the cylinder

$w$ : Mean circumference of the damper's annular flow path

$\eta$ : Viscosity

$\mu_{o}$ : Absolute permeability of the vacuum

$\mu_{r}$ : Relative permeability

$\tau_{y}$ : Shear yield stress

$v$ : Piston velocity.

\section{Conflict of Interests}

The authors declare that there is no conflict of interests regarding the publication of this paper.

\section{References}

[1] A. Kumar and S. K. Mangal, "Properties and applications of controllable fluids: a review," International Journal of Mechanical Engineering and Research, vol. 2, no. 1, pp. 57-66, 2012.

[2] J. Rabinow, "The magnetic fluid clutch," Transactions of the AIEEE, vol. 67, pp. 1308-1315, 1948.

[3] E. J. Park, D. Stoikov, L. Falcao da Luz, and A. Suleman, "A performance evaluation of an automotive magnetorheological brake design with a sliding mode controller," Mechatronics, vol. 16, no. 7, pp. 405-416, 2006.

[4] G. Peng, Development of MR fluid damper for motorcycle [M.S. thesis], University of Wollongong, New South Wales, Australia, 2011.

[5] W. H. Li, H. Du, and N. Q. Guo, "Finite element analysis and simulation evaluation of a magnetorheological valve," International Journal of Advanced Manufacturing Technology, vol. 21, no. 6, pp. 438-445, 2003.

[6] J. C. Dixon, The Shock Absorber Handbook, John Wiley \& Sons, London, UK, 2nd edition, 2007.

[7] http://www.lord.com/.

[8] J. D. Carlson, D. M. Catanzarite, and K. A. S. Clair, "Commercial magneto-rheological fluid devices," International Journal of Modern Physics B, vol. 10, no. 23-24, pp. 2857-2865, 1996.

[9] Z.-D. Xu, D.-H. Jia, and X.-C. Zhang, "Performance tests and mathematical model considering magnetic saturation for magnetorheological damper," Journal of Intelligent Material Systems and Structures, vol. 23, no. 12, pp. 1331-1349, 2012.

[10] Engineering Note-Designing with MR Fluids, Lord CorporationThomas Lord Research Center.

[11] X. Wang and F. Gordaninejad, "Dynamic modeling of semiactive ER/MR fluid dampers," in Smart Structures and Materials 2001: Damping and Isolation, Proceedings of SPIE, pp. 82-91, March 2001.

[12] X. Jiang, J. Wang, and H. Hu, "Designing and modeling of a novel magneto-rheological fluid damper under impact load," in Proceedings of the International Conference on Mechanical Engineering and Mechanics, pp. 203-207, Beijing, China, 2009. 

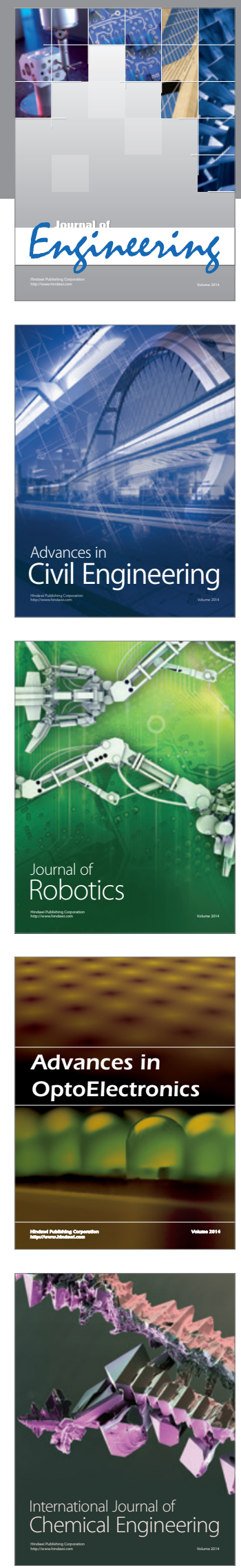

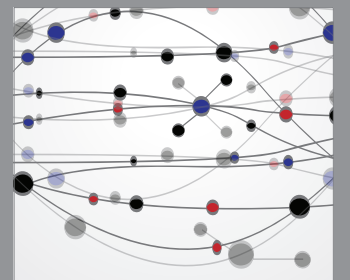

The Scientific World Journal
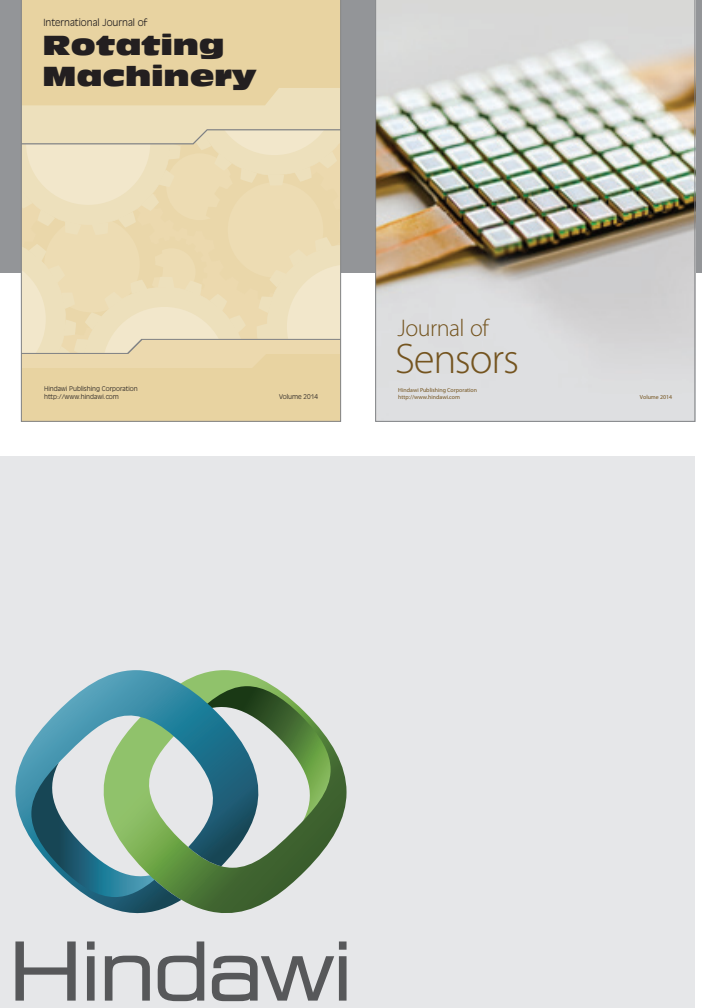

Submit your manuscripts at http://www.hindawi.com
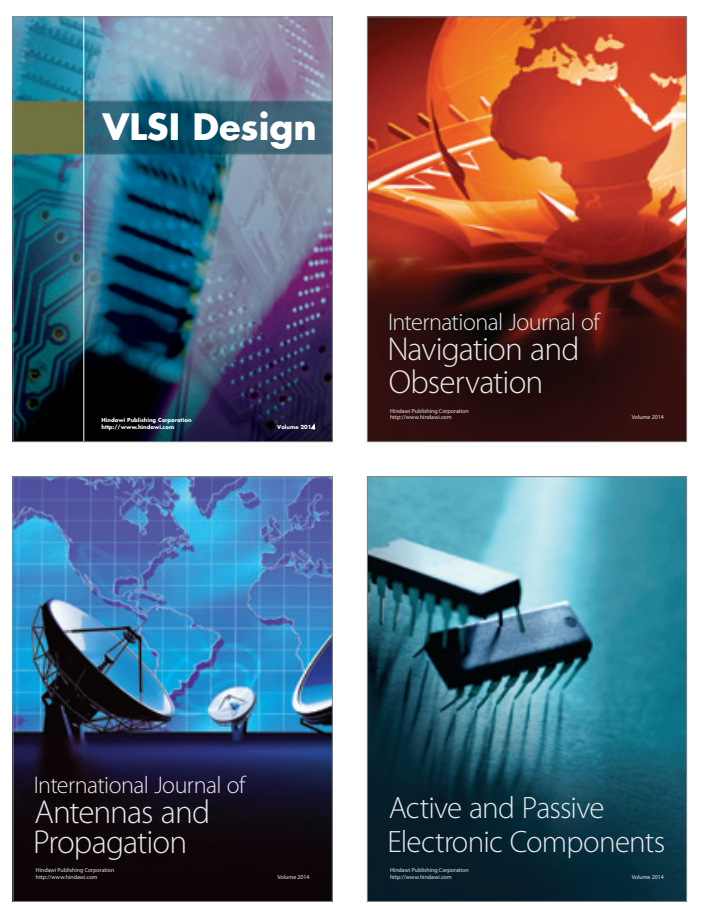
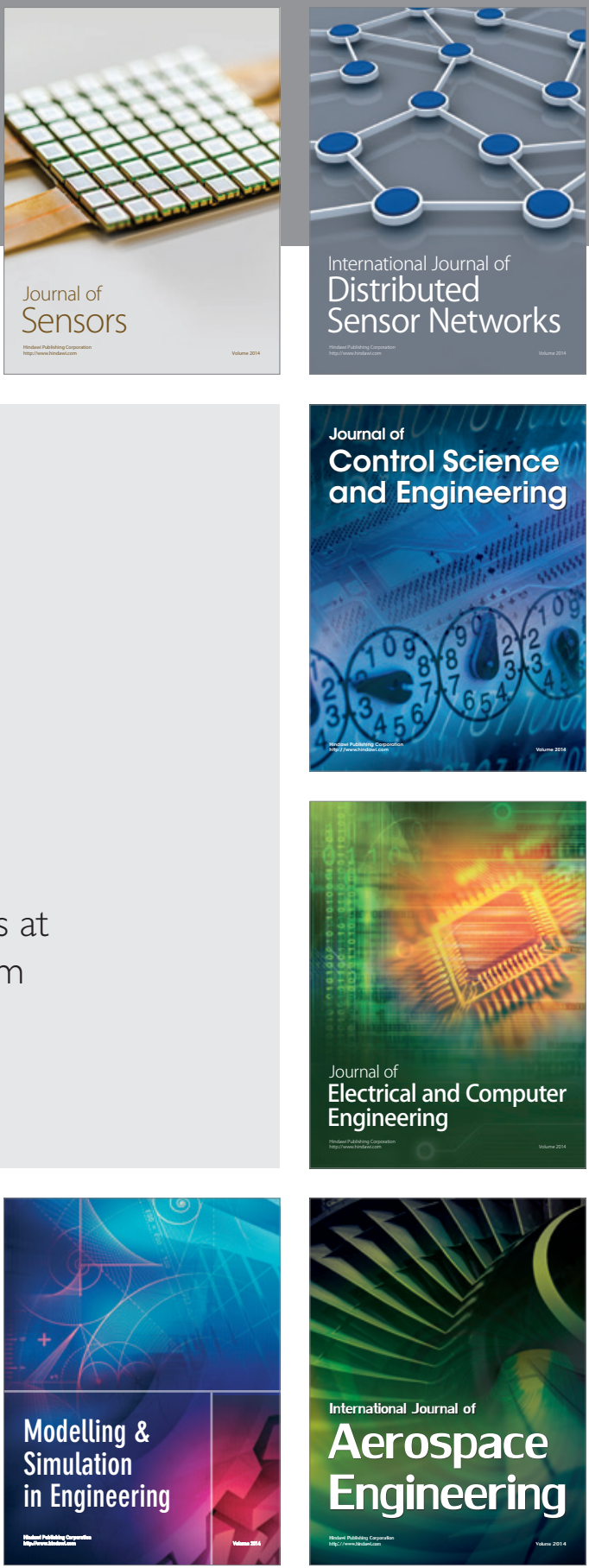

Journal of

Control Science

and Engineering
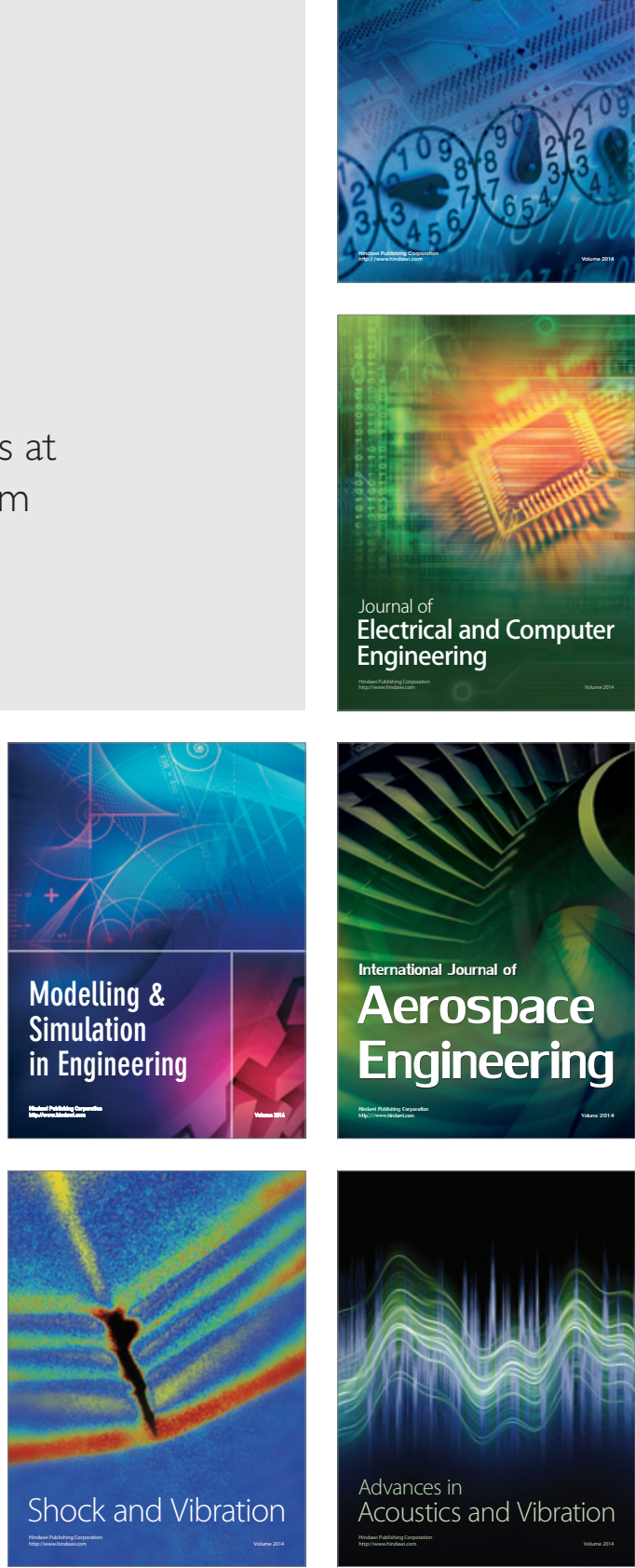